\title{
The Empire Struck Back: Cross-Cultural Communication in a Multilingual Classroom
}

\author{
Mathew Bumbalough
}

\begin{abstract}
This pilot study explores language identity in the field of World Englishes as international students in a multilingual writing classroom encounter a Westerncentric teaching environment while struggling to become a part of the World English speaking community. In this instance, the students were able to bring their cultural and linguistic identities into the classroom in order to make meaning, and joined a community of practice that took into consideration their agency and L1 identities. Based on my initial classroom observations, I identified a pair of students to interview in order to triangulate and confirm my findings. By conducting semistructured interviews, analyzing paper topics, and learning about the participants" backgrounds, I was able to determine that while English was important to each of them in different ways, their identities were what was most important of all. Through an analysis of their interactions and interviews I assert that they are, in a true sense, speakers of World Englishes who are struggling to create their language identities as they bring their cultural and linguistic capital into the classroom to deal with any issues they face. As a result, there were several gaps I noticed between (western) teaching practices and the World Englishes the students speak. While this is a pilot study, I hope to further investigate my findings in a full ethnography that will expand on the issues in this paper.
\end{abstract}

Keywords: qualitative research; world Englishes; multilingual; identity; learner agency

\section{Introduction}

In Salman Rushdie's essay “The Empire Writes Back with a Vengeance” (1982), he says that colonies that were part of the British Empire are now claiming the English language, and are using it for their own purposes. In fact, the uses of English around the world go much further than the colonies of the former British Empire and are now an area ripe for exploration. It is no surprise that the numbers of international students are increasing in United States universities (Alberts \& Hazen, 2013), and this number will continue to rise. How, then, are we preparing our teachers and students to deal with speakers of other languages who join their classroom? Going a step further, how do we address the issue of using a World English in a classroom that is, more than likely, approaching English from a Western-centric perspective (see Cook, 1997; Jenkins, 2005; Y. Kachru, 1994; Ortega, 2011 \& 2013)? The goal of this paper is to create a dialogue among current definitions of World Englishes (see Bruthiaux, 2003; Jenkins, 2006; B. B. Kachru, 1988; Schneider, 2003), 
explore Bourdieu"s notion of academic capital (see Bourdieu, 1990 \& 1993; Calhoun, LiPoma, \& Postone, 1993), and investigate Bernstein"s (1999) vertical and horizontal discourses. This exploration is a pilot study more than a full classroom ethnography, but I examine how World Englishes (WE) are used by analyzing and interpreting the results from the study using an ethnographic approach along with field notes, interviews, and writing topics in a multilingual undergraduate writing classroom in order to find gaps in pedagogical practices in a classroom that uses multiple WE. By showcasing how students bring their language identities into their interactions with other students, the teacher, and the text, I demonstrate how educators can increase student engagement and create opportunities for prudent teaching practices in a guided and supportive space. This study contributes to the conversation of WE by bringing to light those instances of meaningmaking when a student critically engages with other students using their cultural and language identities, and showing how pedagogy affects the classroom environment. Through this study I hope to spark a conversation that will lead to larger ethnographic studies that could contribute to the dialogue of WE in Western classrooms.

To bridge the gap between WE as it shifts the focus from viewing WE through a post-colonial lens and student practices, I took into consideration themes of learner agency, identity, and communities of practice that I observed it in the classroom. As a result I pose the following research questions:

1. How do students identity themselves when they speak English?

2. How are students able to use their agency as they join a community of practice?

3. What would a model of WE look like that takes into consideration language identity?

I also briefly explore some teaching practices that resulted in confusion between the instructor and the students.

\section{Defining World Englishes and Language Identity}

\section{Current Definitions and Models of World Englishes}

Over the past five decades there has been an increasing trend of research conducted on the use of English around the world, and there are several models that attempt to make sense of which countries use English. B. B. Kachru (1985) offered the first theoretical model of how nations make use of English through his concept of the three concentric circles. In the inner circle are the "norm setting" countries, or countries that were the colonizers. This includes the United States and the United Kingdom. In the outer circle are those countries that were former colonies of the inner circle, or countries such as India, and the Philippines. B. B. Kachru (1985) claims that these colonies use English as a result of their colonialism. The expanding circle includes those countries that are not former colonies but use English to some degree, such as Japan, Finland, or Brazil.

While this model certainly makes it easier to categorize and label countries based on how they use English, it still lumps speakers of English into groups, making it easier to apply labels that might not fit individuals. Bruthiaux (2003) takes a very critical view of this model, as, after a deeper analysis, it only scratches the surface of what English use around the world looks like, and separates countries based on nationality, race, and politics more than any academically balanced definition. On the other hand, Jenkins (2006) defines 
WE as English as it is used in the outer circle. I find myself drawn to the "umbrella label" that covers every type of English (including English as a lingua franca) around the world and all of the ways that Englishes are labeled and analyzed (Jenkins, 2006, p. 159; Bolton, 2004, p. 367). I believe this definition helps break down any barriers that were unwittingly put up by B. B. Kachru's (1985) model, as well as fitting better with the pilot study that I conducted, since not all of the students I interviewed came from former colonial countries. Therefore, in this paper I use the "umbrella label" definition of WE, as it best describes the English I encountered in the pilot study.

As far as the current models in WE, in the past decade alone there has been an increasing awareness of the significance of WE and the effect they have in the classroom. However, there still remains some hesitancy towards acceptance of WE in academics. Bhatt (2001) called this hesitancy the "sacred cows" of English language education; an expansion of B. B. Kachru's (1985) concept of the state of English education and an attempt by academics to retain the hold on the current status quo in their fields through limiting English to the acquisitional (Western lens of English), sociolinguistic (local varieties of English), pedagogical (how we should model English), theoretical (native vs. nonnative), and the ideological (a standard) (p. 538). Any change in the academic field will not happen overnight, although the increasingly critical turn (read nondeficit notions of English) towards this monolingual bias in the classroom has gained some traction (see May, 2013). In fact, there should be no borders surrounding WE, much like a border surrounding a country (Bolton, 2012). In an age of increasing ease of cross-cultural communication and international travel, it might be misleading to rely on a model that offers limited mobility to countries or people that do not fit a certain criterion.

So where do we turn? Schneider (2003, p. 244) offers a newer model: the Dynamic Model of Postcolonial Englishes that relies on five stages of English development in a specific region, rather than relying wholly on the sociohistorical (or postcolonial) implications about that territory. These five stages still depend on the use of English in previously colonized countries, and while they can be applied to countries that have not undergone a period of occupation, Schneider (2014) did not originally intend for the model to do so (p. 17). Furthermore, he even goes so far as to say that the model might not be feasible for describing the "dynamism of global English," or the countless uses of English around the world. Instead, he calls for labeling the rise in popularity of English as a "transnational attraction" (pp. 27-28). This term seeks to define those who learn English as learning for the sake of simple attraction, and peripheralizes those who speak a WE but are not in one of the "recognized" countries where English is used socially on a daily basis. While there may be shortfalls in the current models of WE, there seems to be a prevailing theme in literature: the importance of language identity (see Bolton, 2012; House, 2003; Norton, 2013 for examples).

The classroom is not a static place; it is dynamic as identities clash, and the environment changes as students use their agency and position to negotiate meaning and increase their comprehension of another language. Even among the students I interviewed, English took on a hierarchy in their lives based upon their need to join a community. 


\section{Language Identity}

Language identity is the desire of the speaker of a language to belong (Norton, 1997; West, 1992). This language identity in WE then realizes the desire to fit into a group that uses a language as a means of belonging, usually coming before any allegiance to culture or home. In order to belong to this language community, there must be a set of criteria that the user meets. First, the user must be part of a group that uses English as a means of communication, or a community of practice (see Wenger, 1988). This group can rise above a physical location, unfettered by physical borders, or it can be as small as the classroom setting where I conducted my study. This is more than a speech community, since in a multilingual classroom students might not share similar linguistic and cultural backgrounds that make up said speech community (see Gumperz, 2001). Secondly, the individual must not be "forced" to join the group. Third, he/she must self-identify as a member of the community. Language identity is personal, and it must be up to the individual to decide whether or not he/she wants to join. I propose that meeting these three criteria and using English as a means of communication will determine whether an individual has the language identity of a WE user in a specific community of practice.

Given this presupposition, how would this ideology interweave with current theories of academic practice, and how would that theory exist outside of any bookshelf in a university library? Bloome and Hardy (2012) say that "there is no theory outside of action" (p. 133). In short, how could the actions I observed in my pilot study be reflective of current theories that would support the ideology that belonging as a member to a WE community is based on identity?

\section{Bourdieu and Linguistic Capital}

Linguistic capital is the attempt by the dominant (in this study, speakers of a Western English) to hold onto an official standard which students try to emulate (Bourdieu, 1991). Another way to explain it would be Language and a language (Milson-Whyte, 2013), a way of creating a clear distinction between a standard (Western) English and (nonstandard) WE. The educator would assume dominance in their field of power (Bourdieu, 1993, p. 16), or the classroom, while their students would be agents in the field, unaware of the influence of symbolic violence which encourages them perform to a certain standard. The symbolic violence in the classroom is the unconscious transmission of the dominant Language in order to influence or change the social and cultural perception of the students. While not physical, the symbolic violence is powerful, as it puts the students in a hierarchy of us (the students) vs. them (the teacher). In the multilingual classroom, students who speak a form of "nonstandard" English, or WE/ELF, are marginalized as their English would be seen as deficient, lacking certain cultural or societal nuances that would allow them to join the dominant class. As well, there is a tendency by the dominant to keep the dominated in their position in the field; symbolic violence that once again is brought about usually unknowingly by the dominant. Even as students strive to reach the sort of competence that educators expect, there is still an expectation about what competence is.

Canagarajah (2013) defines competence not as simply additive (Language over a language), but as the "transformative capacity to mesh their resources for creative new forms and meanings" (p. 2). By thinking about competence as a form of translanguaging, or 
flexible bilingualism, it helps to delineate literacy as not being just about the academic ability to read or write, but as a way that students bring personal linguistic and cultural capital into a classroom, meshing the two in a linguistic and cultural dance. The effects of this competence on current pedagogy is not difficult to see, as I noticed in my study, but the implications of looking at competence in this light helps to shed some of the Westerncentric practices that we sometimes see in the classroom.

Furthermore, it is important for a researcher to use this same sort of competence in describing theory as it relates to a multitude of cultures around the world. While a Bourdieusian approach might work for describing the symbolic violence and domination seen in the Western classroom, will that same approach work in a multilingual setting? How would a classroom with a diverse international population with individual linguistic and cultural characteristics feel about Bourdieu's concept of symbolic violence? A Chinese student who comes from a traditional family could see subjugation as a necessary part of life. Filial piety, for example, could be a form of sociocultural identity in which taking care of parents or listening to those who are older than you is an expected social practice (Hwang, 1999). I believe the key word is "expected." As symbolic violence is unknowingly committed, once it becomes an expectation, is it still symbolic violence? I believe not, as there needs to be a conscious effort to maintain filial piety. Going against the expectation would be seen as an act of rebellion against family rather than a chance to throw off the shackles of political or social hierarchy. With that in mind, I would say that the concept still works in the context of this study, but would need to be reconsidered if the same study were to be conducted overseas in a monolingual L1 environment or in a wholly nonWestern setting. Furthermore, researchers must be aware of the various cultural and linguistic nuances of their theories, as what might be considered symbolic violence in one region might not be in another. In other words, they must know something about the students' L1. Domination itself might have different meanings, and it would be perhaps dishonest to assume that it would have the same meaning in, for example, America as it does in China.

Where, then, can we use linguistic and cultural capital to show instances where meaning is made and where domination occurs? As I said, I believe it does not need to be in a purely Western setting, but in the context of this study, my own lens is perhaps "Westernized" to see it that way. As a statement of reflexivity, I have to admit that as an educator, researcher, and student, I see the world differently than the students I observed. In short, the problems that I see might not be the same problems that the students see. However, throughout my observations and interviews, I hoped to achieve a sense of understanding about language identity, monolingual bias, and linguistic/cultural capital as I explored more deeply what it meant to be a speaker of a WE in a multilingual classroom. While the lens may not be perfect, I hope it can shed some light on the issue of learner agency and the pedagogical practices that we use in increasingly multilingual classrooms. 
Bumbalough Page $\mid 27$

\section{Methodology}

\section{The Classroom}

I began my pilot study in a writing class designed for international undergraduate students, and I followed those students as they completed their course of study. The particular class I was able to observe had 16 students, all of them speakers of English at various levels. Although the majority were Chinese (13 students), others came from Korea (2 students) and Greece (1 student). As a result, the Chinese students tended to speak their native language before, during, and after class with their peers, while the other three were entirely reliant on English to converse with others. The seating arrangement and classroom groups were split up in such a way that the Korean students were not able to talk during class, and the student from Greece could only rely on her English ability. For my nonparticipant observations, I sat in the back left corner of the classroom, a vantage point from which I was easily able to see and listen to all of the students as they worked individually and in groups. To increase the strength of my pilot study it was important to find a classroom like this (multilingual) that provided at least two case study participants in the same classroom. While this study is small in nature, I believe that selecting a representative of the classroom minority juxtaposed with a classroom majority student should lead to more credible results. There were a large number of L1 Chinese speakers, and I chose to observe and interview two students in the class, a Chinese student and a Korean student. In order to protect their privacy as well as the instructor's, the students were assigned pseudonyms, and the data and their identities were kept private.

\section{Observations, Interviews, and Data Analysis}

The pilot study was conducted from March 2014 to April 2014. The first day in the classroom, I introduced myself to the students and explained very briefly the purpose of my study. I did not ask for volunteers for interviews right away, as I first wanted them to become comfortable with my presence in the classroom. I made sure to sit near the back, where I had a good vantage point from which I could watch the students as they worked in groups to complete projects and review grammar and writing with the instructor. Based on these initial observations, I picked out two students who participated the most in the classroom and who were most eager to conduct an interview with me. In addition, the two students helped me to redefine my research questions and break down some of the preconceptions about what I would find during my study. Overall, they were both instrumental in bringing a clarity and richness to my research that might otherwise be missing. After selecting and obtaining permission from these two students, I conducted one-on-one semistructured interviews (see Appendix A), asking about their linguistic background, how they saw themselves as speakers of English, why they chose certain topics to write about, why they might use their L1 in the classroom, how they interacted with other L1 speakers outside of the classroom, and why they decided to study English. I followed these initial interviews with further questions via email, and later allowed them to read and respond to the transcripts of their answers to the initial interview questions. During the initial and follow-up interviews, I made sure to take into consideration what I had observed them doing in the classroom, making certain that my interpretation of their actions aligned with how they perceived their actions. 


\section{Participant Backgrounds}

Junjie is a Turkish-Chinese freshman majoring in chemistry. He grew up in the Han region of China with a half-Turkish mother and a Han Chinese father. As a result, he sees himself as a minority in China, and seemed hesitant during the interviews to talk about his linguistic history. Further questioning revealed that he spoke Turkish until the age of four before starting to learn Chinese. What is interesting to note is that when he speaks Chinese, he identifies with nerd culture and enjoys technology, but when he speaks English he says he is more sociable. In explaining why he felt this way, he let me know that when he speaks English, he purposefully changes his personality in order to "fit in" with his idea of Western culture. This was not what I was expecting, and Junjie continued to surprise me throughout the interviews. While he aspires to be a doctor someday, he realizes that he has many hurdles to overcome as an international student to achieve his goal. This is his first year studying abroad, and he watches dramas and TV shows in order to learn English. While growing up in China, his English education was "mute," or focused on listening to the instructor, so he never had the chance to actually practice speaking English before he moved to the United States. He sees himself staying in the US for as long as he can and has little aspiration to return to China. For his final paper, he chose to write about GLBT marriage in China.

Eunhee is a Korean freshman majoring in Psychology. She comes from Seoul but has lived the past several years in the US. When she was fifteen, she came to the US in order to attend high school at her father's urging. She enjoys herself in the US, but still sees herself as a Korean person who just uses English as a means of communication, rather than a Korean who uses English to engage with others on a deeper level. She does not interact with the other Korean student in the classroom, but she has many Korean friends she sees daily when attending church and other social functions. Because of this, she speaks mostly Korean throughout the day and tends to congregate with other Koreans at the university. During the class she works with Junjie in a small group to talk about the classroom readings and get feedback on writing projects. Eunhee's final paper was on baby boxes in Europe, but touched on abandoned babies in Korea as well. Her father pushed her to learn English from an early age, and her ability is quite good. She enjoys working in small groups but feels there are some things, such as the use of Chinese among Chinese students and allowing more time for collaboration, that could be managed better in the class. Also, she wishes she could read more examples of past student work to gauge where she is and what she needs to do to become a better writer.

The last person I interviewed was the instructor. She has lived overseas for a number of years in Europe both as a teacher and a student, and this was reflected by her using examples of studying overseas in a foreign context as a way of relating to her students. By doing so she was able to engage well with the students in the short amount of class time, and provided concise instructions and examples throughout my observation.

\section{Findings}

Through the initial observations I was able to start coding instances where the students brought up the importance of English to their own lives, reflected in their choice of group interactions and final paper topics. As I collected more data, I began to code instances in my 
field notes that focused on three major themes: the multilingual classroom as a community of practice, the importance of L1 identity, and any instances of learner agency through their engagement with others in the class.

\section{Community of Practice}

In analyzing the community of practice for this classroom I took the approach offered by Wenger (1998), taking note of three aspects of interactions, including 1) mutual engagement, 2) joint enterprise, and 3) shared repertoire (p. 2). While these themes developed organically through my observations, I used this model as a way to frame what I saw.

Insofar as the mutual engagement in the classroom, there were many instances of group work and participation. When observing group work I noticed that the students established a standard for working together as teams, and worked through any problems collaboratively. In some cases the groups would also self-censor if a member of that group operated outside of these norms. One instance of this self-censoring occurred when one of the groups (composed of two Chinese students, including Junjie) was working on reading an excerpt from the textbook to define terms and phrases the instructor wanted them to focus on. One Chinese student was confused about one of the words and asked Junjie, in Chinese, what it meant. While I did not understand what they were saying, I assumed meaning when the student pointed to a word on the page, and then spoke to Junjie. Junjie then told the other student, in English, to "not speak Chinese," and then answered in English what the word meant. When asking Junjie about the practice of speaking Chinese in small groups, he had this to say:

Excerpt 1, April, 2014

Interviewer: I noticed that it's really interesting that only Chinese groups will speak half Chinese, half English. But in uh [multilingual] groups like yours it's usually always just English.

Junjie: We have to, I mean uh you have to respect like the members of your group.

Right? You can talk secretly in your language, kind of wrong.

Both laugh.

Junjie: Oh I, I do notice that as a group they like speak in Chinese, right?

Junie described the practice of speaking in English as just being polite. Most of the students were Chinese, and while there were many instances of translanguaging among the Chinese students, the engagements I observed between the students relied on a set of rules where speaking English was expected, especially in those groups that were truly multilingual. This adherence to a shared set of rules helped the team to coalesce and form a joint enterprise, or a shared understanding of what was expected of them. As Junjie said, "you have to respect the members of your group." This respect was a continual renegotiating of the rules depending on who was in the group, but it is what united them as a team. Finally, the shared repertoire was the use of the textbook, paper topics, and group meetings when the students would influence, define, and contribute to each other's work. There were of course several instances of resistance to the shared repertoire, but the 
sharing of resources and feedback contributed to the shared understanding when there were questions about the text or daily assignments.

\section{L1 Identity}

Because there were a substantial number of students who spoke Chinese, it was impossible for the instructor to always stop students from using their L1 and translanguage. My interview with the instructor revealed the following:

Excerpt 2, April, 2014

Interviewer: I kind of noticed in the classroom it's, like, you have your groups, like some will be all Chinese and there's two groups that are mixed or three groups. Did you do that on purpose?

Instructor: Well that's the way I did it. There's just so many people to go around and I probably put them into groups. But I can't really be picky about it in case there weren't enough students from countries other than China to mix the groups. I guess in the classroom, though, I could've mixed it up a little bit more. It's just that I have them in their peer groups.

Interviewer: Yeah. Well it was funny that when I was observing the class, the Chinese groups would kind of use English and Chinese. Kind of code meshing a little bit.

Instructor: Yeah, I talked to them about it and, "yeah, it's just so weird to talk in English," and "I know, I know, I know." I try to say that they need to use English so ... "can you just humor me here?"

Speaking English was part of the expected classroom rules. It is an English writing class, and further questioning revealed that most of the students only spoke English during that class. Their L1 identity had to take a backseat to their L2, creating resistance but not an insurmountable amount. While there might be some censoring of the L1, cultural and social issues that were important to them became a cornerstone of how the classroom worked.

Excerpt 3, April, 2014

Interviewer: It seems like a lot of them are bringing global or local issues into the classroom too. I noticed there are about two or three issues about Indiana University and the rest had to do with uh, you know, kind of issues back home almost.

Instructor: Yeah, I know one student who is doing it for the fashion industry but that, her home town has a fur factory. Um, pollution.

Interviewer: Yeah, that was a big one of them, four or so students talking about pollution.

Instructor: Yea, um, I kind of want to go there and see. I've heard so much about it and I really just want to go there and see what actually is there. 
Culture and language are inseparable, and by allowing and encouraging and becoming curious about the topic her students picked, she still allowed students expression of the L1 through culture.

\section{Learner Agency Action, Interaction, and Affordances}

During my first day in class the students read an excerpt written by Julie Traves (2005) from This Magazine entitled The Church of Please and Thank You in their textbook (Mangelsdorf \& Posey, 2010), describing the world of English and what it means to be a global speaker of English by taking the speaker's culture into consideration. The quote by Salman Rushdie came up during the discussion, which the students at first seemed puzzled about: "English, no longer an English language, now grows from many roots; and those whom it once colonized are carving out large territories within the language for themselves. The Empire is striking back." (Traves, 2005, section 3 para. 3). Junjie did not know what the last line meant. He asked the instructor for a further explanation, but the instructor explained that it was a reference to Star Wars and did not mention its connection to the British Empire.

Junjie didn't seem content with that answer, but then the students got into groups to discuss what they liked or disliked about the article. The groups were split up in such a way that a Korean student was in groups with other Chinese speakers while Junjie went into a group with two other Chinese speakers. The group was then interrupted as the instructor told them to next discuss the quote "The Empire is striking back". In the same group I watched as they found the quote, read it silently, and gave their answers in English. I was surprised at how different they were. Some thought that it meant using their native languages rather than English, others thought that countries were using their own language, and some thought that it meant the countries had mastered English enough to compete in the global economy.

Overall the students seemed confused about the pop culture reference that was several decades removed from the present. However, they agreed that the quotation means that countries that used to be colonies of the British Empire were now using English for their own purposes, and by doing so are now able to compete in business and education.

By conducting interviews I hoped to find out how the two students viewed themselves as speakers of English and what problems they might face when they confront classroom issues with a Western bias. After much deliberation, I was able to start answering the question of how students in a multilingual classroom bring their own cultural and linguistic capital into play when engaging with other students, and how they are able to overcome any constraining factors that might hinder their understanding. It became clear that the students used English for different purposes: Junjie had aspirations to stay in the US, while Eunhee was just waiting to go back to Korea. Some of the conversations during the interviews turned to the teacher's teaching style, but it helped me to determine what factors led to the gap between a Western-centric model of teaching and the WE the students in the classroom use. Eunhee had this to say about the instructor: 


\section{Excerpt 4, April, 2014}

Eunhee: I think she's really nice person. She's really nice. Um, and she try to make up improve how write an essay and stuff. But uh, I have seen a lot of American like, who teaches English in Korea and also English teacher who when I was in high school. And I found out that she was a little different. Um, uh, like um, I think she should be more specific when she talks about assignment. Not just showing the presentation and just exactly what has just been written on it. More examples that she can make. Like uh...

Interviewer: Like an example of somebody's past work.

\section{Eunhee: Yeah.}

Rather than it being a clear case of monolingual bias, it seemed more about the way students wanted the information presented in the classroom. My two interviews revealed that they knew why they wanted to learn English, and it was for very personal reasons. This is not a critique of the teaching, this is simply my attempt to create a way forward for English educators who are native speakers to become more cognizant of how students are bringing their cultural and language identities into the classroom.

\section{Outcome of the Study}

\section{Discussion}

My findings show that in the multilingual classroom, students are using English for their own purposes, not necessarily the purposes of the university or teacher, depending on the rules established in the community or practice. Furthermore, this shows that although there are similar expectations of the students in the classroom, they negotiate meaning in their own way based upon their sociocultural/linguistic background. Junjie, for example, used English as a means of communicating and joining new social groups. He saw learning English as a way of escaping minority status in China and knew he had to learn it in order to stay in the US. Eunhee, on the other hand, saw English only as a means of communication. She was involved in Korean groups and spoke English only when she had to in class. They both enjoyed the classroom but wanted to claim English for different purposes. The differences in why they study English were reflected in their paper topics, interactions with other students, and affordances they took during the class.

The community of practice was different for Junjie and Eunhee, as well. The instructor's rules for group work meant not speaking in the L1 and staying on topic. Junjie followed these rules, and if he joined a group of other Chinese students, he made a conscious effort to speak English, causing some exasperation among the Chinese students who wished to translanguage. For him the classroom rules were the same as the rules in the community that students formed in small groups. Eunhee never sat with the other Korean student in the class, so for her, speaking English was by default; she had to obey the rules of the classroom since she didn't share another language with the other people in her groups. While both of them followed the rules of the classroom and therefore the rules of the community, they did so for different reasons and with different results. Junjie was irritated other Chinese students, while Eunhee seemed to work fine in groups. 
The L1 identity of each interviewee was different as well. Eunhee came from Seoul and spoke Pyojunmal (an accent of Korean seen as "High" language), granting her a place in Korea as a speaker of the majority dialect. She had many Korean friends on campus and was content to use English simply as a means of communication. She had also lived in the US for several years and was comfortable with both languages, giving her a more solidified identity. Junjie, on the other hand, grew up speaking Turkish before he learned Chinese at the age of four. He sees himself as a minority and avoided going to a university in the US South, as he had preconceptions about racial biases there. English for him became a means of escape from the dominated and a chance to join the dominating. He self-censored many more times than Eunhee, and his identity was ever-shifting depending on which language or culture he found himself in or using.

I noticed instances of learner agency through the actions, interactions, and affordances Junjie and Eunhee took with other students in the classroom. Junjie was more withdrawn when with Chinese speakers, speaking only in English and content to take notes and listen rather than engage. The other Chinese students also seemed less interactive with him than with other Chinese students, pushing him into a peripheralized social corner over the course of my observations. However, when in a multilingual group he was much more interactive, speaking the most, and eager to please. Eunhee was happy no matter which group she was in, and caused many of her group members to laugh about what she had to say. Her personality also seemed the same when we spoke together in Korean during the interview, and I saw her agency as consistent with how she used language and culture.

\section{Limitations}

Throughout the course of my study, there were several limitations. The largest is that the study sample was quite small and covered a short time period. A deeper analysis over a longer period of time would help to refine any misconceptions on my part about what I saw, and the lack of quantifiable data will be worrisome to some groups. As this is a pilot study and not a full ethnography, this is perhaps the largest limitation of all. I hope my study will lead me or others to conduct further studies examining the phenomenon of WE used in a Western classroom. Another limitation is that the model that I used to view WE might not work in all circumstances. This could be for several reasons, but one is that it relies on a Western view of WE and language identity. I had to take time to explain to my interviewees what I meant by identity, and they still seemed confused until I told them it was "how they felt when they used English." Finally, the identity model of WE I am proposing is not really a model, but more of an ethnographer's tool kit for looking at WE. I do this on purpose, as I believe a nonstatic model will engage a more holistic understanding of WE.

\section{Future Directions: Bridging the Gap between What We Know and What We Do}

Although I approach the use of Western-centric education with a Western-centric lens, I believe that researching the teaching of English as a second or foreign language in a Western environment does have merit. Furthermore, we know that that a larger percentage of international students are coming to the US to study each year, and we as teachers must tackle the idea that a monolingual approach to English education with students who speak a variety of WE is not conducive to helping bridge the gaps between 
cultures. As a result, teachers need to practice an informed pedagogy that makes use of the community of practice, the L1 identity, and learner agency in order to bridge any gaps from a wholly Western approach to education. I see informed pedagogy in this case not as knowing the theories behind teaching, but getting to know your students and what they are invested in. In looking forward, I see the results of this pilot study being instrumental in laying groundwork for a further longitudinal ethnography with multiple participants at multiple sites. Furthermore, I see the use of a community of practice as being a powerful tool to describe what I witnessed as a part of this study.

\section{References}

Alberts, H.C., \& Hazen, H.D. (Eds.). (2013). International students and scholars in the United States: Coming from abroad. New York, NY: Palgrave Macmillan.

Bernstein, B. (1999). Vertical and horizontal discourse: An essay. British Journal of Sociology of Education, 20(2), 157-173.

Bhatt, R. (2001). World Englishes. Annual Review of Anthropology, 30, 527-550.

Bloome, D., Hardy, C., Grenfell, M., Pahl, K., Rowsell, J., \& Street, B.V. (Eds.). (2013). Language, ethnography, and education: Bridging new literacy studies and Bourdieu. London, UK: Routledge.

Bolton, K. (2004). World Englishes. In A. Davies \& C. Elder (Eds.), The Handbook of Applied Linguistics (369-396). Oxford, UK: Blackwell.

Bolton, K., (2012). World Englishes and linguistic landscape. World Englishes, 3(1), 30-33.

Bolton, K., \& Kachru, B.B. (Eds.). (2006). World Englishes: Critical concepts in linguistics (Vol. 2). London, UK: Routledge.

Bourdieu, P. (1990). The logic of practice. Stanford, CA: Stanford University Press.

Bourdieu, P. (1991). Language and symbolic power. Cambridge, MA: Harvard University Press.

Bourdieu, P. (1993). The field of cultural production: Essays on art and literature. New York, NY: Columbia University Press.

Bruthiaux, P. (2003). Squaring the circles: Issues in modeling English worldwide. World Englishes, 13(2), 159-178.

Canagarajah, A.S. (Ed.). (2013). Literacy as translingual practice: Between communities and classrooms. London, UK: Routledge.

Calhoun, C., LiPuma, E., \& Postone, M. (Eds.). (1993). Bourdieu: Critical perspectives. Chicago, IL: University of Chicago Press.

Cook, V. (1997). Monolingual bias in second language acquisition research. Revista Canaria de Estudios Ingleses, 34(1), 35-50.

Gumperz, J.J. (2001). The speech community. In A. Duranti (Ed.), Linguistic anthropology: A Reader (pp. 66-74). Malden, MA: Blackwell. 
House, J. (2003). English as a lingua franca: A threat to multilingualism? Journal of Sociolinguistics, 7(4), 556-578.

Hwang, K.K. (1999). Filial piety and loyalty: Two types of social identification in Confucianism. Asian Journal of Social Psychology, 2(1), 163-183.

Jenkins, J. (2005). Implementing an international approach to English pronunciation: The role of teacher attitudes and identity. TESOL Quarterly, 39(3), 535-543.

Jenkins, J. (2006). Current perspectives on teaching world Englishes and English as a lingua franca. TESOL Quarterly, 40(1), 157-181.

Kachru, B.B. (1985). Standards, codification and sociolinguistic realism: The English language in the outer circle. In R. Quirk \& H.G. Widdowson (Eds.), English in the world: Teaching and learning the language and literatures (pp. 11-30). Cambridge, UK: Cambridge University Press.

Kachru, B.B. (1988). The sacred cows of English. English Today, 16(4), 3-8.

Kachru, Y. (1994). Monolingual bias in SLA research. TESOL Quarterly, 28(4), 795-800.

Mangelsdorf, K., \& Posey, E. (2010). The world of writing: A guide. London, UK: Longman.

May, S. (Ed.). (2013). The multilingual turn: Implications for SLA, TESOL, and bilingual education. New York, NY: Routledge.

Milson-Whyte, V. (2013). Pedagogical and sociopolitical implications of code-meshing in classrooms: Some considerations for a translingual orientation to writing. In S. Canagarajah (Ed.), Writing as translingual practice in academic contexts. New York, NY: Routledge.

Norton, B. (1997). Language, identity, and the ownership of English. TESOL Quarterly, 31(3), 409-429.

Norton, B. (2013). Identity and language learning: Extending the conversation (2 ${ }^{\text {nd }}$ ed.). Bristol, UK: Multilingual Matters.

Ortega, L. (2011). Reflections on the learning-to-write and writing-to-learn dimensions of second language writing. Learning-to-Write and Writing-to-Learn in an Additional Language, 31, 237.

Ortega, L. (2013). Ways forward for a bi/multilingual turn in SLA. In S. May (Ed.), The multilingual turn: Implications for SLA, TESOL, and bilingual education. New York, NY: Routledge.

Rushdie, S. (1982, July 3). The Empire writes back with a vengeance. The [London] Times, p. 8.

Schneider, E.W. (2003). The dynamics of new Englishes: From identity construction to dialect birth. Language, 79(2), 233-281.

Schneider, E.W. (2014). New reflections on the evolutionary dynamics of world Englishes. World Englishes, 33(1), 9-32. 
Traves, J. (2005, March-April). The Church of Please and Thank You. This Magazine. http://www.thismagazine.ca/issues/2005/03/church.php

Wenger, E. (1998). Communities of practice: Learning as a social system. Systems Thinker, 9(5), 2-3.

West, C. (1992). Identity: A Matter of Life and Death. October, 61, 20-23. 